Slavica

bruxellensia

\section{Slavica bruxellensia}

Revue polyphonique de littérature, culture et histoire

slaves

$1 \mid 2008$

Théâtre

\title{
Iaroslav Lebedynsky, Ukraine. Une histoire en questions
}

Jeremy Lambert

\section{OpenEdition}

Journals

Édition électronique

URL : http://journals.openedition.org/slavica/245

DOI : $10.4000 /$ slavica. 245

ISSN : 2034-6395

\section{Éditeur}

Université libre de Bruxelles - ULB

\section{Édition imprimée}

Pagination : 71

ISSN : 2031-7654

Référence électronique

Jeremy Lambert, «laroslav Lebedynsky, Ukraine. Une histoire en questions », Slavica bruxellensia [En ligne], 1 | 2008, mis en ligne le 15 octobre 2008, consulté le 22 septembre 2020. URL : http:// journals.openedition.org/slavica/245; DOI : https://doi.org/10.4000/slavica.245

Ce document a été généré automatiquement le 22 septembre 2020.

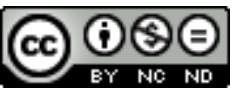

Les contenus de Slavica bruxellensia sont mis à disposition selon les termes de la Licence Creative Commons Attribution - Pas d'Utilisation Commerciale - Pas de Modification 3.0 France. 


\section{Iaroslav Lebedynsky, Ukraine. Une histoire en questions}

Jeremy Lambert

\section{RÉFÉRENCE}

Iaroslav Lebedynsky, Ukraine. Une histoire en questions, Paris, L'Harmattan, Présence Ukrainienne, Série « Sciences Humaines », 2008, 271 p. 
1 Divisé en dix chapitres chronologiques, cet ouvrage analyse l'évolution historique de l'Ukraine dans sa complexité éthique par le biais de cent trente-cinq questions qui deviennent au fil de la lecture autant de repères conceptualisants. Les nombreux renvois qui émaillent le texte assurent une heureuse cohérence. Chaque question fait l'objet d'une réponse concise mais complète dans laquelle l'auteur n'hésite pas à comparer les différentes thèses historiosophiques, démêlant ainsi l'écheveau de considérations souvent contradictoires relatives à son objet. Mythes et légendes, anciens ou repris (Roxolanie, Sarmatie, etc.), sont abordés de manière à souligner l'évolution culturelle d'un peuple multiple en quête d'unité; un éclairage intéressant est appliqué aux concepts de "Cosaque», «Ruthène» et «Petit Russien» notamment. Vingt-trois cartes

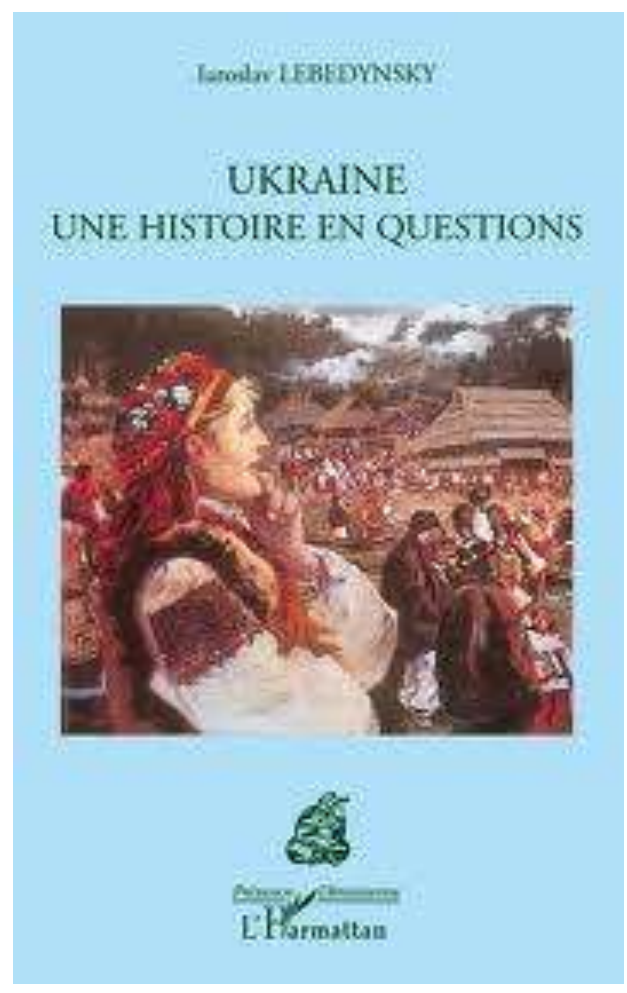
géographiques viennent compléter ces informations.

2 Livre foisonnant et compact, cette œuvre de vulgarisation historique permet d'approfondir les connaissances relatives à l'histoire de l'Europe orientale. La vision transversale appliquée par l'auteur à l'étude de l'Ukraine se révèle un complément à haute valeur ajoutée à l'histoire de la Pologne et de la Russie, deux nations par le biais desquelles est plus régulièrement évoquée l'Ukraine.

Iaroslav Lebedensky, le directeur de la collection «Présence Ukrainienne », se défend dès l'introduction de proposer une somme historique. Les notes de bas de page sont absentes, tout comme la bibliographie. Ce parti pris justifié par la volonté de proposer un livre introductif innovant est cependant un point faible. Aussi la facture est-elle fragilisée par quelques coquilles résiduelles.

Il s'agit donc de considérer cet ouvrage comme il se doit: une intelligente vulgarisation, qui demande d'être complétée par des études précises, mais qui intéressera l'étudiant curieux de la réalité slave dans toute sa complexité.

\section{INDEX}

Index géographique : Ukraine

Mots-clés : histoire de l'Ukraine 


\section{AUTEURS}

\section{JEREMY LAMBERT}

Doctorant en Langues et Littératures Slaves ; membre du Centre d'Études en Civilisations,

Littératures et Lettres Étrangères (CECILLE) de l'Université Charles-de-Gaulle Lille3 ; membre du comité de rédaction et rédacteur technique de «Slavica Bruxellensia » 